\title{
TRANSSEPTAL LEFT HEART CATHETERIZATION
}

\author{
BY
}

\author{
B. LYNN MILLER* AND W. E. MEDD $\dagger$
}

From the Cardiac Department, St. Thomas' Hospital

Received January 26, 1963

Left heart catheterization by puncture of the atrial septum was introduced by Manfredi (1956) and elaborated by Ross (1959). We have investigated 65 patients by this method and present our results with particular reference to its safety and effectiveness.

\section{SubJECTS AND METHOD}

The majority of the patients had rheumatic heart disease (Table I). The age range was 9 to 67 years and the distribution is shown in Table II. There were three patients under 17 years of age. The size of the left atrium was graded on X-ray (penetrated postero-anterior, right lateral, and right anterior oblique views with barium in the œsophagus) and was found to be normal in 11, slightly enlarged in 23 , moderately enlarged in 29 , and aneurysmal in 2 patients.

The basic technique of transseptal left atrial puncture used was that described by Ross, Braunwald, and Morrow (1960). Briefly, this consists of introducing a $59.5 \mathrm{~cm}$. long catheter into the right atrium from the right saphenous vein, threading the $61 \mathrm{~cm}$. transseptal needle (Fig. 1) through the catheter and puncturing the septum in the region of the fossa ovalis with the needle. It has not always been found possible to make contact with the atrial septum in the lower half of the right atrial shadow as advised by Ross since a small left atrium frequently lies higher. When this is the case it is considered especially important to maintain the $45^{\circ}$ posterior slant of the needle at puncture since the aorta is at the same level but anterior to the left atrium. The entire procedure is done under fluoroscopic control, and blood samples and pressure pulses are taken through the needle immediately before and after the puncture to confirm the position of its tip.

When, in ten of the earlier cases of the series, information was required from the left ventricle as well as the atrium, an attempt was made to obtain it by passing a thin polythene tube through the needle once its tip was lying in the left atrium (Ross et al., 1960). This procedure was unsatisfactory in our laboratory and was abandoned in favour of advancing the large catheter over the needle after the tip of the needle has been introduced into the atrium. The procedure evolved in our laboratory whereby the needle is held stationary while the catheter is advanced differs slightly from that described by Brockenbrough and Braunwald (1960) and Gorlin et al. (1961) in which the needle and catheter are advanced together for a short distance with the needle point protruding before the catheter is further advanced over the needle. Once the catheter is in the left atrium the needle is withdrawn to the point of puncture and the catheter advanced into the ventricle. The needle is then removed and all the pressure measurements under rest and exercise conditions and the blood samples required in the individual case are obtained, and contrast injection is performed if indicated.

When right heart catheterization was indicated it was performed through the same vein either after the left heart catheterization ( 40 patients) or simultaneous with it (6 patients). The bleeding that tended to occur at the site of the venous incision when two catheters were introduced simultaneously was controlled by a clamp across the vein between the catheters.

After finding that it was possible to advance the large catheter into the left atrium, it became apparent that certain characteristics of the number 9 NIH catheter that had been employed in the first 32 cases were not ideal for this new use. Thus, once in the left atrium it was difficult to get a sharp enough curve into it to direct its tip towards the mitral valve. The catheter was therefore changed to a specially shaped length of yellow Kifa radiopaque polythene tubing (external diameter 2.8 and internal diameter $1.5 \mathrm{~mm}$.) (Fig. 1),

* Now at National Institute of Cardiology, Av. Cuauhtemoc No. 300, Mexico 1, D.F., Mexico. $\dagger$ Now at Kingston Hospital, Kingston-on-Thames, Surrey. 
TABLE I

Case Material by Diagnosis

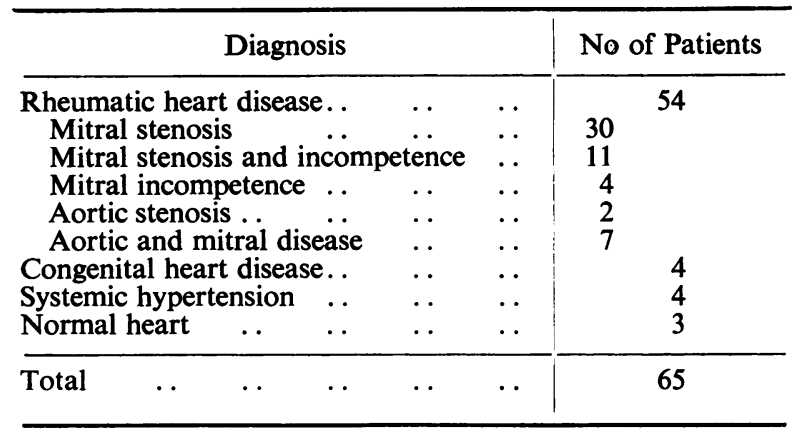

TABLE II

Case Material by Age

\begin{tabular}{c|c}
\hline Age (yrs.) & No. of patients \\
\hline$<31$ & 10 \\
$31-40$ & 16 \\
$41-50$ & 24 \\
$>50$ & 15 \\
\hline Total & 65 \\
\hline
\end{tabular}

the general properties and handling of which were described by Ödman (1959). This catheter retains the deep curve in the distal end at body temperature and this facilitates its manipulation into the left ventricle. It does, however, require the added precaution of withdrawing the catheter enough to straighten its curve before advancing the needle in order to avoid piercing the side wall of the catheter. This catheter can also be tapered at the tip to ease the advance through the septum and the proximal end can be flared to fit a Seldinger adaptor making a connexion strong enough to withstand contrast injection.

\section{RESULTS}

The left atrium was entered with the needle in $54(83 \%)$ of the total group of 65 patients in whom transseptal left atrial puncture was attempted. The rate of success rose to 91 per cent for the second half of the series probably due to the greater experience of the operators. The incidence of successful studies bore no relation to the diagnosis or age of the patients or to the size of the left atrium.

The technique was unsuccessful in the investigation of 11 patients for various reasons. In 5 it was not possible to get both the catheter and the needle as far as the right atrium; in 2 it was impossible to pass the catheter into the inferior vena cava; in 3 the bend taken by the catheter at the junction of the common iliac vein with the inferior vena cava could not be straightened sufficiently to allow passage of the needle; and in one of these the inferior vena cava was to the left of the spine.

In 5 other unsuccessful studies the right atrium was entered but it was not possible to make satisfactory contact with the atrial septum. In 2 of these the reasons were obvious, one being a mediastinal shift to the left, and the other the left saphenous approach which was found to direct the needle towards the lateral wall of the right atrium rather than towards the septum. There was no apparent reason for failure to make firm contact with the septum in 2 cases. In 1 further case the only firm contact with the septum was high in the cardiac shadow and no puncture was made because of the increased risk of puncture of the aorta at this level. The remaining unsuccessful attempt at transseptal puncture was due to a calcified left atrial wall, the force usually required to pierce the septum merely causing a dent.

Once the needle was in the left atrium the procedure was simple and there was not a single failure in advancing the catheter over the needle in the 33 cases in which it was attempted. This was usually successful at the first attempt but in 3 cases it was necessary to repeat the septal puncture. In 13 of these 33 patients information was also required from the left ventricle and in all the catheter was easily manipulated into the ventricle.

Selective left heart angiograms were obtained in 10 patients, with injection into the atrium in 7 and into the ventricle in 3, and the structures of interest were well outlined in every case. An example of a left ventricular angiocardiogram is shown in Fig. 2. This experience with left heart angiography is given in more detail by Macdonald and Miller (1962).

There was no mortality in this series. Morbidity consisted of low back-ache during the procedure in seven patients; this probably arose from traction on the inferior vena cava since it 

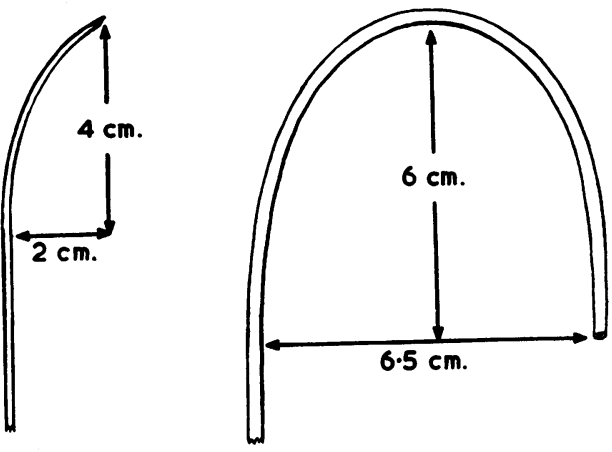

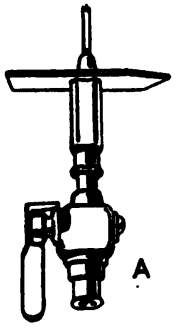

Fig. 1.-Equipment for transseptal puncture: A. Transseptal needle. B. Specially prepared polyethylene catheter. C. Seldinger adaptor.

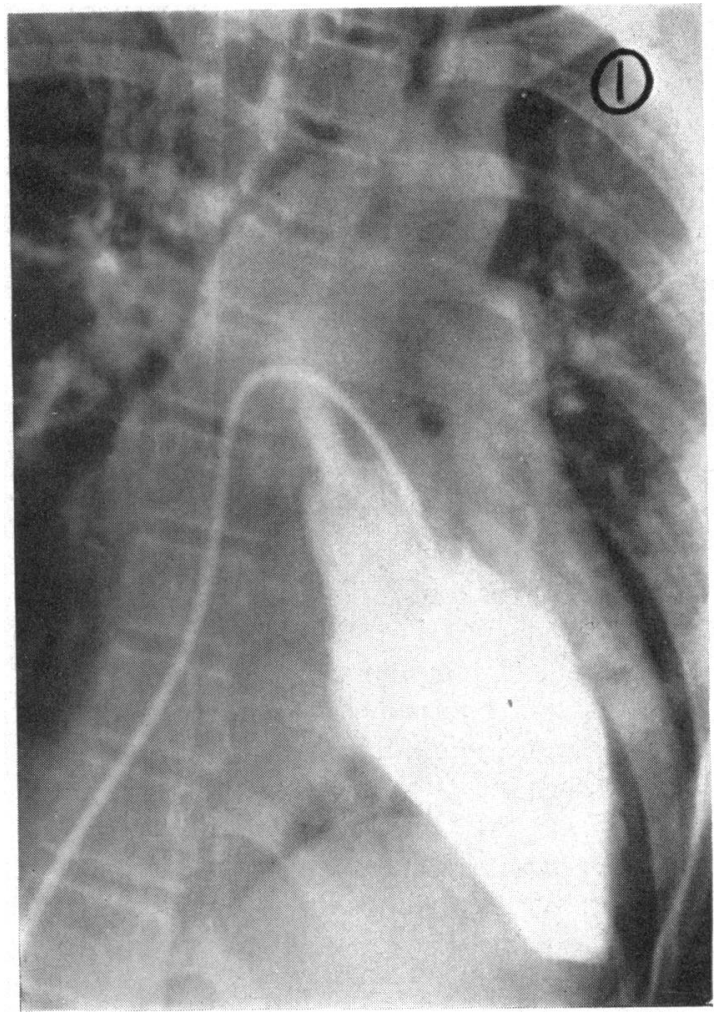

FIG. 2.-An example of a left ventricular angiogram by the transseptal technique in a patient with aortic valve stenosis. (Reproduced by permission of the editor of Clinical Radiology.)

subsided when the needle was removed. There were no instances of aortic puncture. The side wall of the catheter was pierced with the needle on three occasions, once early in the experience with the NIH catheter and twice with the polyethylene catheter, but the patients were unaware of this happening and showed no ill effects.

The hearts of 35 of the 60 patients in whom the needle was advanced as far as the right atrium were subsequently examined at operation after intervals of from two days to several months. There was no evidence of hæmopericardium or pericarditis in any. In two who died after aortic valvotomy, autopsy revealed a small area of bruising on the atrial septum as the only sign of puncture.

\section{Discussion}

Over 1100 catheterizations of the left heart via the transseptal route have been reported (Cope, 1959; Singleton and Scherlis, 1960; Nixon, 1960; Steinhart and Endrys, 1960; Fisher, Logsdon, and McCaffrey, 1960; Bevegård et al., 1960; McGaff et al., 1961; McGuire et al., 1961; Gorlin et al., 1961; Soulié et al., 1961; Reale, 1961; McIntosh et al., 1961; Iliescu et al., 1961; Beuren and Apitz, 1962a; Brockenbrough, Braunwald, and Ross, 1962). This experience cannot be handled as a continuous series with reliable percentage incidence because the unpublished experience may or may not be as favourable. It is, nevertheless, impressive that all published studies have reported this to be a useful technique with a high rate of success and few complications. 
Efficiency of the Method. Higher success rates of left atrial puncture were found by McGuire et al. (1961) with 94 per cent of 81 cases and by Brockenbrough et al. (1962) with 99 per cent success in the last 156 of their 450 investigations by this technique. Certainly the rate of successful studies does improve with experience initially, but we see no reason to expect our success rate to improve much over the 91 per cent for the second half of this series. Since most of the failures are due to inability to pass the catheter and needle into the right atrium from the right leg, it is possible that these patients could be studied by transseptal left atrial puncture approached from the right arm (Fisher et al., 1960) or from the right external jugular vein (Bevegård et al., 1960).

Besides being an improved method of left atrial catheterization this technique as modified allows entry into the left ventricle in a high percentage of cases with a catheter big enough to take reliable pressure recordings and to inject contrast material. In this series information was obtained from the left ventricle in each of the 13 patients in whom it was desired. Since we did not experience any failure in advancing the catheter into the left atrium or ventricle as desired, it emerges that the rate of success in entering these chambers with the catheter depends chiefly on the rate of success of right atrial catheterization and left atrial puncture which in the second half of our series was 91 per cent. Brockenbrough et al. (1962) reported 95 per cent success in catheterizing the left ventricle by a similar technique of advancing a large catheter. Comparison of these figures with the 71 per cent of Singleton and Scherlis (1960) and 80 per cent of McGuire et al. (1961) for the technique of blindly passing a fine polyethylene tube through the left atrial needle reveals one of the advantages of the modification.

An additional advantage of the transseptal technique is that right heart catheterization can be done through the same venous cut down. Furthermore, Singleton and Scherlis (1960) and Brockenbrough et al. (1962) have found that it is possible to catheterize even the aorta by this approach by passing a thin polyethylene tube through the transseptal apparatus, but the reliability for this purpose remains unknown. The transseptal technique has been applied to left-sided intracardiac phonocardiography by Beuren and Apitz (1962a).

Risks. In this series of 65 patients the procedure was without mortality or important morbidity. There are, however, serious complications to be found in the other reported series. There are two instances of hæmopericardium. One occurred as the only major complication in a series of 450 cases reported by Brockenbrough et al. (1962), where the patient developed hypotension shortly after puncture of the aorta and recovered after pericardial aspiration and transfusion: the second, reported by Reale (1961), was treated by immediate thoracotomy for decompression and valvotomy and also made a full recovery without the site of bleeding being established. The only mortality from the reported series was a patient with severe aortic stenosis and a history of angina and syncope who one hour after investigation developed hypotension, violent constricting chest pain, and ventricular tachycardia (Soulié et al., 1961).

Apart from the above reports from large series we are aware of three isolated examples of severe complications. One death due to hæmopericardium from puncture of the free wall of the left atrium, in a patient who was having heparin and phenindione, occurred 36 hours after the procedure (E. N. Spira, 1961, personal communication). Another patient became severely hypotensive coincident with transseptal puncture, developed signs of a left hemiparesis, and died five days later: autopsy showed moderately extensive hæmorrhage of the atrial septum and a massive acute rightcerebral infarction with old occlusive vascular disease of the right common carotid artery (R. C. Schlant, 1961, personal communication). There has also been a report of cardiac arrest probably following cerebral and coronary emboli, but this patient, treated by external cardiac compression, made a full recovery (Nixon, 1961).

Comparison with Other Methods. It is difficult to compare the transseptal technique with the other methods of left heart catheterization since most series published have been small, the material studied has been heterogeneous and seldom has a single group of investigators reported on more than one method. In addition some of the experience reported may have been selected for publication because of particular success or failure. However the following provisional conclusions seem 
warranted. Transseptal left heart catheterization appears to be safer than posterior percutaneous left atrial puncture and anterior percutaneous left ventricular puncture. Furthermore, initial experience of about 120 cases (Steinhart and Endrys, 1960; Braunwald et al., 1962; Beuren and Apitz, 1962b; Paulin and Varnauskas, 1962; Macdonald and Miller, 1962) suggests that selective left angiography by the transseptal technique does not carry a greatly increased risk and this is to be compared with the high risk of angiography by the posterior percutaneous method (Bagger, Björk, and Malström, 1957) and by the anterior left ventricular puncture method (Björk and Lodin, 1959). The transseptal technique may, on the other hand, carry a slightly higher risk than bronchoscopic left atrial puncture which has been shown to be safe over a large series (Morrow, Braunwald, and Ross, 1960), but in our experience the left ventricle is more reliably entered by the modified transseptal method and, in addition, the patient is in a more basal condition. Suprasternal left atrial puncture provides only limited information since it does not safely allow any access to the left ventricle nor contrast injection. The retrograde arterial technique is reasonably safe (Dotter and Gensini, 1960), although a few complications and even deaths have been reported, and is the procedure of choice for angiography in aortic regurgitation. The retrograde technique, however, has a lower rate of success in catheterizing the left ventricle in cases of aortic valve stenosis, and it seems that the transseptal technique is preferable for investigation of left ventricular outflow tract obstruction.

\section{SUMMARY AND CONCLUSIONS}

Experience in performing transseptal left heart catheterization in 65 patients is recorded. A modification of the original technique is described in which a large polyethylene catheter is advanced over the transseptal needle into the left atrium and ventricle. This catheter allows satisfactory pressure recordings, at rest and exercise, blood sampling, and contrast injections. The left atrium was entered in 83 per cent of cases and no significant complications occurred in this series. The possible complications of the method are discussed. It appears that this technique, as modified, is the most generally applicable method of left heart catheterization developed thus far.

The transseptal method of left heart catheterization as modified has the advantage of allowing access to all four chambers of the heart through a single vein in a reasonably high percentage of cases. Its greatest value lies in left ventricular catheterization since this chamber has been the one least readily and safely accessible. Pressure records and blood samples can be taken under basal and exercise conditions and contrast injections can be performed. The method is comparatively complex and experience with it is likely to give an increasing incidence of successful studies. It is emphasized that when the contact of the needle with the septum is entirely satisfactory, i.e. in the lower half of the cardiac shadow and with the needle tip pointing postero-medially, the risk of the procedure is probably very low, and if these conditions do not prevail the worth of the information to the patient should be reassessed. In view of the occasional serious complication the technique should only be used if the information sought cannot be obtained by simpler means.

Our thanks are due to Dr. J. Ross, jun., who demonstrated his technique to one of us (W.E.M.) who was on a visit to Dr. A. G. Morrow's Laboratory at the National Heart Institute, Bethesda, Maryland, in October, 1959. We are also grateful to Drs. E. N. Spira, W. B. Hood, jun., and D. Mendel for their co-operation in some of the cases, and to Mr. J. Gibbons, Mrs. P. Stranbridge, and Miss M. Anthony for technical assistance.

The transseptal needle is available from Chas. F. Thackray Ltd., 38 Welbeck St., London W.1. The Kifa radiopaque polyethylene catheter and the Seldinger adaptor are available from Sierex Ltd., 15 Clipstone Street, London
W.1.

\section{REFERENCES}

Bagger, M., Björk, V. O., and Malmström, G. (1957). Technique and sequelæ of catheterization of the left side of the heart. Amer. Heart J., 53, 91.

Beuren, A. J., and Apitz, J. (1962a). Modification of the technique of transseptal catheterization of the left heart. Z. Kreisl-Forsch., 51, 11. and $-(1962 \mathrm{~b})$. Selective transseptal angiocardiography of the left atrium or left ventricle. Z. Kreisl.-
Forsch., 51, 20. 
Bevegård, S., Carlens, E., Jonsson, B., and Karlöf, I. (1960). A technique for transeptal left heart catheterization via the right external jugular vein. Thorax, 15, 299.

Björk, V. O., and Lodin, H. (1959). Left heart catheterization with selective left atrial and ventricular angiocardiography in the diagnosis of mitral and aortic valvular disease. Prog. cardiovasc. Dis., 2, 116.

Braunwald, E., Brockenbrough, E. C., Talbert, J. L., Folse, J. R., and Rockoff, S. D. (1962). Selective left heart angiocardiography by the transseptal route. Amer.J. Med., 33, 213.

Brockenbrough, E. C., and Braunwald, E. (1960). A new technic for left ventricular angiocardiography and transseptal left heart catheterization. Amer. J. Cardiol., 6, 1062.

,$- \frac{1}{-}$, and Ross, J., Jr. (1962). Transseptal left heart catheterization. A review of 450 studies and description of an improved technic. Circulation, $25,15$.

Cope, C. (1959). Technique for transseptal catheterization of the left atrium: preliminary report. J. thorac. Surg., $37,482$.

Dotter, C. T., and Gensini, G. G. (1960). Percutaneous retrograde catheterization of the left ventricle and systemic arteries of man. Radiology, 75, 171.

Fisher, D. L., Logsdon, G. R., and McCaffrey, M. H. (1960). Use of a sharp stylet for interatrial septal passage of the radiopaque right heart catheter into the left heart. Circulation, 22, 749.

Gorlin, R., Krasnow, N., Levine, H. J., Neill, W. A., Wagman, R. J., and Messer, J. V. (1961). A modification of the technic of transseptal left heart catheterization. Amer. J. Cardiol., 7, 580.

Iliescu, C. C., Kleinerman, L., Ştefănescu, T., Ghiţă, M., Bandu, I., Efraim, I., and Guţă, G. (1961). Left heart catheterization by the transseptal route. (Cateterismul inimii stîngi pe calea transseptală.) Med. interna. (Buc.), $13,1485$.

Macdonald, J. S., and Miller, B. L. (1962). Selective transseptal angiocardiography of the left side of the heart. Clin. Radiol., 13, 195.

Manfredi, D. (1956). Un nuovo catetere per lo studio fisiopatologico del cuore sinistro. Arch. ital. Chir., 81, 409.

McGaff, C. J., Roveti, G. C., Glassman, E., and Ross, R. S. (1961). An experience with transseptal left heart catheterization. Amer. Heart J., 61, 161 .

McGuire, L. B., Hyland, J. W., Harrison, D. C., Haynes, F. W., and Dexter, L. (1961). Experience with transseptal left heart catheterization. Amer. Heart J., 62, 288.

McIntosh, H. D., Whalen, R. E., Hernandez, R. F., Morris, J. J., and Miller, D. E. (1961). A potential hazard of the transseptal left atrial catheterization technic. Amer. J. Cardiol., 8, 835.

Morrow, A. G., Braunwald, E., and Ross J., Jr. (1960). Left heart catheterization: an appraisal of techniques and their applications in cardiovascular diagnosis. Arch. intern. Med., 105, 645.

Nixon, P. J. F. (1960). The transeptal approach to the left atrium in mitral regurgitation. Thorax, 15, 225.

(1961). The arterial pulse in successful closed-chest cardiac massage. Lancet, $2,844$.

Odman, P. (1959). The radiopaque polyethylene catheter. Acta. Radiol. (Stockh.), 52, 52.

Paulin, S., and Varnauskas, E. (1962). Selective transseptal angiocardiography. Acta radiol. (Stockh.), 57, 3.

Reale, A. (1961). Il cateterismo del cuore sinistro per via transettale. Cuore e Circol., 45, 265.

Ross, J., Jr. (1959). Transeptal left heart catheterization. A new method of left atrial puncture. Ann. Surg., $149,395$.

-, Braunwald, E., and Morrow, A. G. (1960). Left heart catheterization by the transseptal route: a description of the technique and its applications. Circulation, 22, 927.

Singleton, R. T., and Scherlis, L. (1960). Transseptal catheterization of the left heart: observations in 56 patients. Amer. Heart J., 60, 879.

Soulié, P., Servelle, M., Forman, J., Osty, J., Baledent, P., and Eagle, C. C. P. (1961). Le cathétérisme des cavités gauches par voie transseptale. Arch. Mal. Cour, 54, 481.

Steinhart, L., and Endrys, J. (1960). Die transseptale Lävographie. Fortschr. Röntgenstr., 93, 753. 